\title{
Aerobic Biodegradation of 2-Picolinic Acid by a Comamonas Sp.
}

\author{
Wang Qiaorui, Zheng Chunli*, Fan Yurui, Shen Zhenxing, Han Wenhao and Du Miaomiao
}

Department of Environmental Science and Engineering, Xi' an Jiaotong University, Xi'an 710049, PR China

\begin{abstract}
A strain was able to use 2-picolinic acid (2-PA) as a sole source of carbon, nitrogen and energy under aerobic conditions was isolated in this paper. Based on 16S rRNA gene sequence analysis, this strain was identified as Comamonas $s p$. and named as ZD3. The effects of $\mathrm{pH}$ and initial concentrations of 2-PA on the degrading capacity of ZD3 were investigated. It was found that ZD3 degraded 2-PA effectively under a pH range of 5.0 to 9.0 , in which 7.0 was proved to be the optimal value. When the initial concentration of 2-PA was $100,200,400,600$ and $800 \mathrm{mg} / \mathrm{L}$, ZD3 completely degraded 2-PA within 10, 18, 22, 78 and $114 \mathrm{~h}$, respectively. Zero order kinetic model expressed the degradation behavior of 2-PA by ZD3 well. It was observed that under the concentration range of 100 to 400 $\mathrm{mg} / \mathrm{L}$, the degradation rate constant increased with the increase in concentration and reached the maximum at 400 $\mathrm{mg} / \mathrm{L}$. However, under the concentration range of 600 to $800 \mathrm{mg} / \mathrm{L}$, the degradation rate constant began to decrease, indicating an inhibitory effect. Moreover, ultraviolet scanning and high performance liquid chromatography ion trap timeof-flight mass spectrometry showed that during the degradation of 2-PA the first reaction was $\alpha$ hydroxylation so that 6-hydroxy picolinic acid (6-HPA) was produced.
\end{abstract}

Keywords: Comamonas sp.; 2-Picolinic acid (2-PA); Aerobic; Biodegradation

\section{Introduction}

Pyridine and its derivatives belong to N-heterocyclic compounds. Pyridine-contained wastewater mainly stems from mining, coal and shale oil industry processing, wood preservative treatment, medicine and food industry, dye manufacture and agricultural production, etc. $[1,2]$. Due to its high toxicity and carcinogenicity, pyridines are listed as priority-controlled pollutants by United States Environmental Protection Agency [2]. 2-Picolinic acid, a kind of pyridine compounds, is intensively used for the manufacture of pharmacy, pesticides, daily chemical products, and additives of animal husbandry foods $[3,4]$. On account of high hydrophilicity (solubility $=887 \mathrm{~g} / \mathrm{L}, 20^{\circ} \mathrm{C}$ ), 2-PA can steadily and persistently exist in water body and consequently endangers the environment. Recent studies have reported that the aerobic biological method is able to effectively remove 2-picolinic acid from wastewater [5], and the microbes mainly belong to the genera of Arthrobacter [6], Bacillus [7], and Streptomyces [8]. However, quantitatively describing the degradation process of 2-PA by microbes are still absent. Moreover, it is also unknown that whether 2-PA can be utilized by other species of microorganism or not $[1,2]$. In this paper, a strain was able to use 2-PA as a sole source of carbon, nitrogen and energy under aerobic conditions was isolated. Its cell morphology and homology analysis based on nucleic acid sequence were carried out. Environmental factors which influenced the degradation process of 2-PA were investigated, and consequently the degrading kinetic models were established in order to quantitatively describe the degradation capacity of this new strain. The purpose of this paper is to provide a scientific basis for the decontamination of wastewater loaded with 2-PA.

\section{Materials and Methods}

\section{Chemicals}

Both 2-PA (97\%) and formic acid (95\%) were of chromatographical purity and purchased from Sigma-Aldrich (American). Methanol (97\%) was brought from the Fisher Chemical (American). Other reagents were of analytical purity. Ultrapure water was prepared by SPI-11-10T apparatus (resistivity=18 $\mathrm{M} \Omega-\mathrm{cm}$ ).

\section{Isolation and identification}

The activated sludge used in this work was collected from a wastewater treatment plant (located in Xi'an, Shaanxi Province, China) that treated wastewater contaminated with 2-PA. A certain volume $(10 \mathrm{~mL})$ of the activated sludge was aseptically added to $90 \mathrm{~mL}$ of the sterilized MS medium ( $\mathrm{pH}=7.0$ ) [9] in a $250 \mathrm{~mL}$ flask. The $250 \mathrm{~mL}$ flask was supplemented with 2-PA with a concentration of $100 \mathrm{mg} / \mathrm{L}$ and placed in a rotary shaker (ZHWY-2102C, Zhicheng Analytical Instrument Manufacturing Co., Ltd., Shanghai, China) at $180 \mathrm{r} /$ min and $30^{\circ} \mathrm{C}$. When the culture became obviously turbid, $10 \mathrm{~mL}$ of the culture was transferred to $90 \mathrm{~mL}$ fresh MS medium in a new 250 $\mathrm{mL}$ flask with $100 \mathrm{mg} / \mathrm{L} 2$-PA. This cultivation was repeated until the degradation of 2-PA came to a stable level, and then the culture was diluted with sterilized $\mathrm{NaH}^{2} \mathrm{PO}^{4}-\mathrm{K}^{2} \mathrm{HPO}^{4}$ buffer $(\mathrm{pH}=7.0)$ and spread onto agar (1.5\%) plates with MS medium and $100 \mathrm{mg} / \mathrm{L}$ 2-PA. The agar plates were incubated at $30^{\circ} \mathrm{C}$ for 2-3 d. Three colonies appeared on the agar plates and stain ZD3 was selected for the further study.

The 16S rRNA gene sequence of strain ZD3 was amplified by PCR with primers 27F (5'-AGTTTGATCMTGGCTCAG-3') and 1492R (5'-GGTTACCTTGTTACGACTT-3'). PCR mixtures contained template (genomic DNA $20-50 \mathrm{ng} / \mathrm{L})(0.5 \mu \mathrm{L}), 2.5 \mathrm{mM}$ dNTP $(1 \mu \mathrm{L})$, $10 \times$ buffer (with $\left.\mathrm{Mg}^{2+}\right)(2.5 \mu \mathrm{L}), 27 \mathrm{~F}(10 \mu \mathrm{M}, 0.5 \mu \mathrm{L}), 1492 \mathrm{R}(10 \mu \mathrm{M}$, $0.5 \mu \mathrm{L}$ ), $\mathrm{d} \mathrm{H}^{2} \mathrm{O}$ (up to $25 \mu \mathrm{L}$ ), and Dream Taq-TM DNA Polymerase $(0.2 \mu \mathrm{L})$. The PCR instrument used was a 2720 thermal cycler (Applied Biosystems, ABI, USA), the electrophoresis instrument used was a DYCP-31DN (Beijing Liuyi Instrument Factory, China), and the electrophoresis image-forming instrument used was a FR980 (Shanghai

*Corresponding author: Zheng Chunli, Department of Environmental Science and Engineering, Xi' an Jiaotong University, Xi'an 710049, PR China, Tel: 00862982663839; E-mail: clzheng@mail.xjtu.edu.cn

Received August 22, 2017; Accepted August 28, 2017; Published September 03, 2017

Citation: Qiaorui W, Chunli Z, Yurui F, Zhenxing S, Wenhao H, et al. (2017) Aerobic Biodegradation of 2-Picolinic Acid by a Comamonas Sp. J Environ Anal Toxicol 7: 499. doi: 10.4172/2161-0525.1000499

Copyright: $\odot 2017$ Qiaorui W, et al. This is an open-access article distributed under the terms of the Creative Commons Attribution License, which permits unrestricted use, distribution, and reproduction in any medium, provided the original author and source are credited. 
Furi Science and Technology Co., Ltd., China). The amplification settings were a starting temperature of $94^{\circ} \mathrm{C}$ for $4 \mathrm{~min} ; 94^{\circ} \mathrm{C}$ for 45 $\mathrm{sec}, 55^{\circ} \mathrm{C}$ for $45 \mathrm{sec}, 72^{\circ} \mathrm{C}$ for $1 \mathrm{~min}, 30 \mathrm{cycles} ; 72^{\circ} \mathrm{C}$ for $10 \mathrm{~min}$; and finally $4^{\circ} \mathrm{C}$ for termination. A partial sequence of the PCR products was determined for the isolate using an ABI PRISM ${ }^{\mathrm{TM}}$ 3730XL DNA Sequencer (Applied Biosystems). BLAST analysis (NCBI) of the forward and reverse sequences obtained for strain ZD3 was performed. The phylogenetic tree was generated using the aligned sequences through the Neighbo-Joining algorithm using the MEGA 6 software.

\section{Degradation of 2-PA}

One loop of strain ZD3 on the agar plates was transferred aseptically to $100 \mathrm{~mL}$ sterilized MS medium $(\mathrm{pH}=7.0)$ in a $250 \mathrm{~mL}$ flask with $100 \mathrm{mg} / \mathrm{L} 2$-PA. After $12 \mathrm{~h}$ of cultivation ten milliliters of the culture was aseptically inoculated into $90 \mathrm{~mL}$ sterilized MS medium in a $250 \mathrm{~mL}$ flask: (1) the $\mathrm{pH}$ of MS medium varied from 4.0 to 12.0 and then supplemented with 2-PA of $100 \mathrm{mg} / \mathrm{L}$; (2) the $\mathrm{pH}$ of MS medium was fixed at 7.0 and then supplemented with 2-PA ranged from 100 to $800 \mathrm{mg} / \mathrm{L}$. These cultures were incubated on a rotary shaker $\left(30^{\circ} \mathrm{C}\right.$, $180 \mathrm{r} / \mathrm{min}$ ). All cultivations were repeated three times. A flask with the same amount of the autoclaved cells $\left(20 \mathrm{~min}, 120^{\circ} \mathrm{C}\right)$ was used as abiotic degradation. Samples were withdrawn periodically for the analysis of 2-PA concentration and total organic carbon (TOC). Prior to the analysis of 2-PA concentration and TOC, samples were centrifuged under $15^{\circ} \mathrm{C}$ at $12,000 \mathrm{r} / \mathrm{min}$ for $20 \mathrm{~min}$ to collect the supernatant which then was filtered through a $0.22-\mu \mathrm{m}$ membrane to remove the biomass.

\section{Analysis}

Residual 2-PA concentration was determined at $265 \mathrm{~nm}$ with high performance liquid chromatography (S600, Sykam, Germany) using a Reprospher 100 C8 $(5 \mu \mathrm{m}, 150 \mathrm{~mm} \times 4.6 \mathrm{~mm})$ (Sykam, Germany). The mobile phase was a mixture of water to methanol (v/v, 90: 10) containing $0.2 \%$ of formic acid. The flow rate was $1 \mathrm{~mL} / \mathrm{min}$ and the column temperature was $30^{\circ} \mathrm{C}$. Mass spectra of 6-hydroxy picolinic acid were acquired using a high performance liquid chromatography ion trap time-of-flight mass spectrometry (HPLC-IT-TOF-MS) (Shimadzu, Japan). The reaction mixtures were precipitated with ethanol and centrifuged $\left(20000 \mathrm{r} / \mathrm{min}, 20 \mathrm{~min}, 4^{\circ} \mathrm{C}\right)$. The supernatants were analyzed by direct insertion mass spectra in the negative mode. Scanning electron microscopy (SEM) was used for the morphology observation and the method was the same as described in Ref. [9].

\section{Results and Discussion}

\section{Isolation and identification}

The morphological characteristics of strain ZD3 on agar plates was shown in Figure 1. It was creamy white and non-transparent with an irregular shape. Its surface was rough and flat. The edge was ragged. The colony closely attached to the surface of agar plates. As presented in Figure 2, the SEM image under 10000 times magnification showed that the cells of strain ZD3 were short rod with a length between 1 and $2 \mu \mathrm{m}$. Based on the phylogenetic tree in Figure 3, it was found that the homology of strain ZD3 (Genbank No. KP900021) between Comamonas $s p$. VT3 reached $100 \%$. Therefore, strain ZD3 was identified as a Comamonas sp. Recent researches have reported that Comamonas sp. can be applied for puring the wastewater contained polycyclic aromatic hydrocarbon $(\mathrm{PAH})$, quinoline, cholesterin, steroids, and nitrobenzene, etc [10]. However, studies on the degradation of 2-PA by Comamonas $s p$. are still limited.

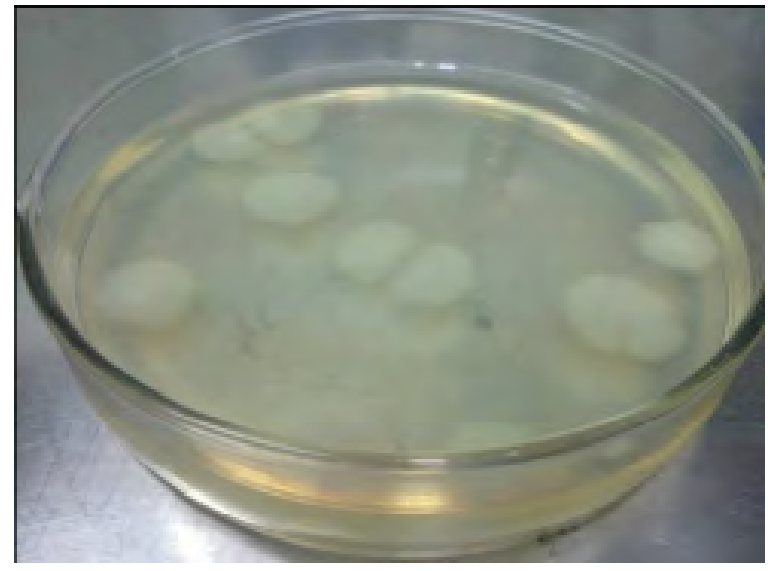

Figure 1: Morphology of strain ZD3 on agar plates.

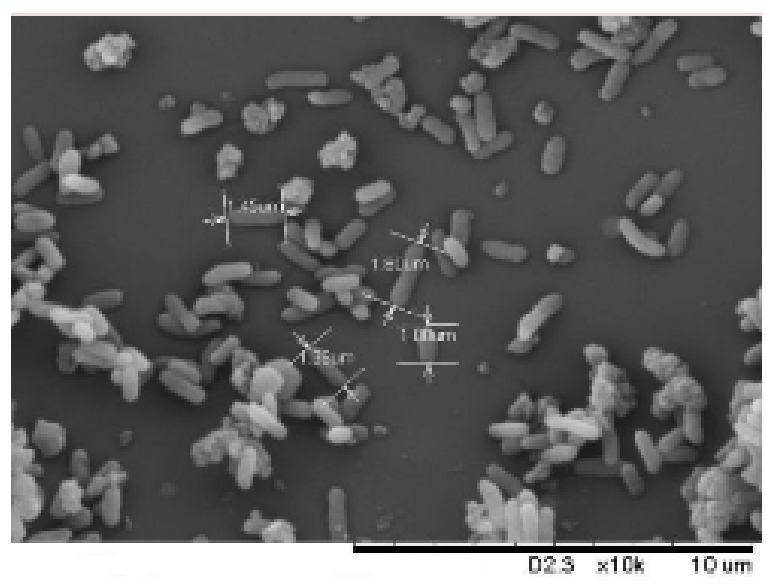

Figure 2: SEM image of ZD3.

\section{Degradtion of 2-PA}

Effect of pH: Evironmental factors which affect the performance of microbial degradation mainly inculde temperature, $\mathrm{pH}$, dissolved oygen (can be expressed by shaking speed), salinity, and initial concentration of substrates [11]. Experimental results suggested that the optimal temperature for the degradation of 2-PA by strain $\mathrm{ZD} 3$ was $30^{\circ} \mathrm{C}$, shaking speed $150 \mathrm{rpm}$, and salinity $0 \%(\mathrm{w} / \mathrm{v}, \mathrm{NaCl})$ (data not shown). In this study, the influences of $\mathrm{pH}$ and intial concentrations of 2-PA were emphasized. As for $\mathrm{pH}$, this paper adopted initial $\mathrm{pH}$ adjustment method and buffer method, respectively. Initial $\mathrm{pH}$ adjustment method was used $\mathrm{HCl}$ or $\mathrm{NaOH}$ for adjusting the $\mathrm{pH}(4.0-10.0)$ of MS medium with 2-PA $(100 \mathrm{mg} / \mathrm{L})$ as a sole carbon, nitrogen and energy source prior to the inoculation of strain ZD3.

As presented in Table 1, it can be concluded that the optimal $\mathrm{pH}$ value was 7.0, in which the degrading rate of 2-PA almost reached $100 \%$ after $12 \mathrm{~h}$. TOC analysis showed that 2-PA was completely mineralized into carbon dioxide and water at $12 \mathrm{~h}$. When the initial $\mathrm{pH}$ was 5.0 or 9.0, inhibitory effect emerged and the completely degrading time was prologed to $48 \mathrm{~h}$. When the initial $\mathrm{pH}$ was 4.0 or $10.0,2-\mathrm{PA}$ was not degraded at all. Moreover, when the initial $\mathrm{pH}$ ranged from 5.0 to 9.0, the value of $\mathrm{pH}$ fluctuated and finally showed a downward trend during the whole degradation process. The possible reason is 2-PA was biotransformed into intermediates with acidic or alkaline so that the value of $\mathrm{pH}$ changed. When the initial $\mathrm{pH}$ was 4.0 or 10.0 , a downward 


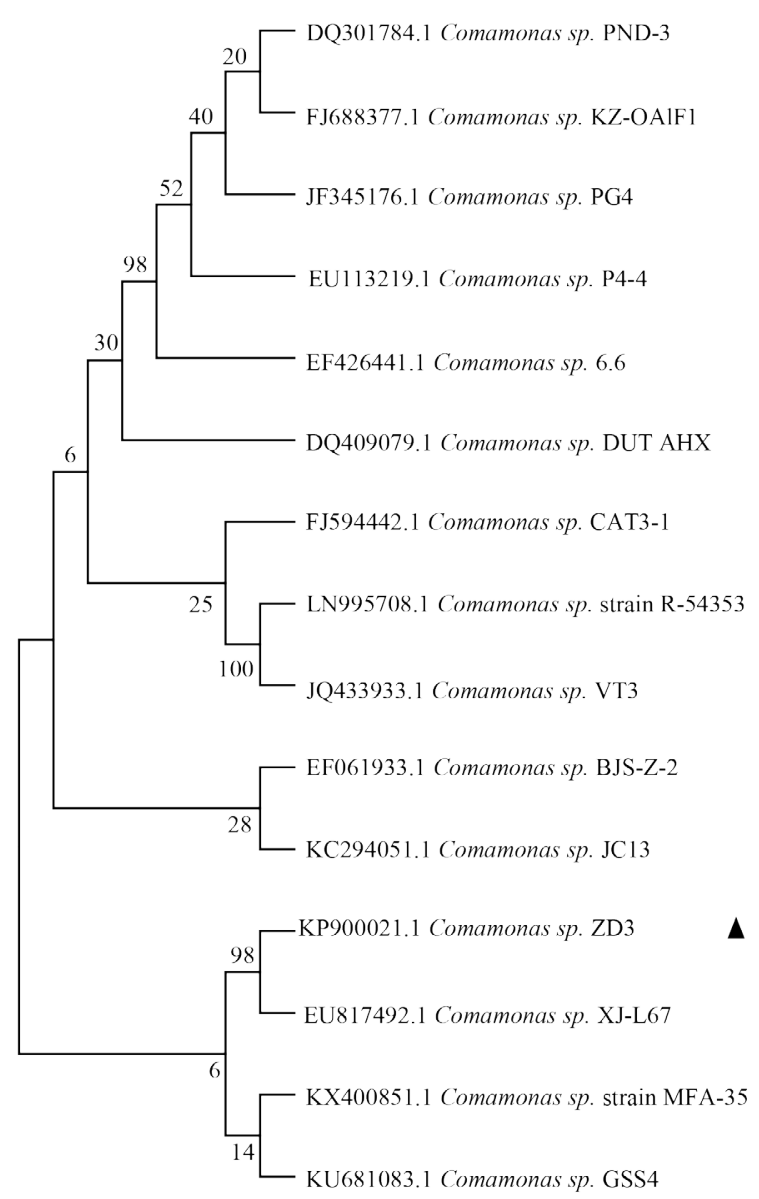

Figure 3: Phylogenetic tree for ZD3.

\begin{tabular}{|c|c|c|c|}
\hline Initial $\mathbf{p H}$ & $\boldsymbol{T}(\mathbf{h})$ & $\mathbf{p H}$ & Removal rate of 2-PA (\%) \\
\hline 4.0 & 12 & 3.57 & 1.4 \\
\hline & 24 & 3.41 & 1.3 \\
\hline & 36 & 3.35 & 1.4 \\
\hline & 48 & 3.40 & 1.5 \\
\hline & 12 & 4.71 & 1.7 \\
\hline & 24 & 4.46 & 17.8 \\
\hline & 36 & 4.87 & 34.5 \\
\hline & 48 & 4.90 & 97.7 \\
\hline 9.0 & 12 & 6.86 & 99.1 \\
\hline & 12 & 8.66 & 2.0 \\
\hline & 24 & 8.69 & 2.3 \\
\hline & 36 & 8.91 & 11.5 \\
\hline & 48 & 8.66 & 98.3 \\
\hline & 12 & 9.88 & 0.1 \\
\hline & 24 & 9.76 & 0.1 \\
\hline & 36 & 9.63 & 0.5 \\
\hline & 48 & 9.65 & 2.0 \\
\hline & & & \\
\hline & & 36 & \\
\hline
\end{tabular}

Table 1: $\mathrm{pH}$ changes and removal rates of 2-PA during the degradation process based on initial $\mathrm{pH}$ adjustment method.

trend of $\mathrm{pH}$ was also observed even no 2-PA was degraded. $\mathrm{pKa}^{1}$ of 2-PA is 1.0 [12]. According to Henderson-Hasselbalch equation, when the initial $\mathrm{pH}$ of MS medium was 4.0 or 10.0, 2-PA was dissociated and in turn proton was released from the carboxyl group of 2-PA so the value of $\mathrm{pH}$ decreased.
As for buffer method, experimental results showed that it was not suitable to use organic buffer solutions since some organic chemicals such as potassium acid phthalate served as a carbon source which in turn disturbed the utilization of 2-PA by strain ZD3. Toxic chemicals such as six methylene tetramine inhibited the activity of ZD3. Thus, inorganic buffer solutions were selected in this paper. From Figure $4 \mathrm{a}$, it was apparent that the value of $\mathrm{pH}$ maintained constantly during the whole degradation process. As shown in Figure $4 \mathrm{~b}$, the degradation rate of 2-PA almost reached $100 \%$ within $10 \mathrm{~h}$ under $\mathrm{pH}$ of 7.0 . When the $\mathrm{pH}$ value equaled to 6.0, 5.0 and 9.0, the completely degrading time was prolonged to $50 \mathrm{~h}, 60 \mathrm{~h}$ and $60 \mathrm{~h}$, respectively. With $\mathrm{pH}$ of 4.0, $10.0,12.0$, all the degradation rates were less than $10 \%$ after $120 \mathrm{~h}$, and the degradation rate was lowest at $\mathrm{pH} 4.0(1.8 \%)$. It was concluded that the degradation performance of 2-PA by strain $\mathrm{ZD} 3$ at different $\mathrm{pH}$ values was in the following order: $7.0>6.0>5.0>9.0>10.0>12.0>4.0$. In addition, the results obtained from initial $\mathrm{pH}$ adjustment method were nearly consistent with them from buffer method.

Influence of the initial concentration of 2-PA: When the initial concentrations of 2-PA were 100, 200, 400, 600 and $800 \mathrm{mg} / \mathrm{L}$, the required time for complete degradation was $10,18,22,78$ and $114 \mathrm{~h}$, respectively (Figure 5). The inhibitory effects became stronger with increase in the initial concentrations. Moreover, the lag phase was also prolonged. Figure 6 showed the ultraviolet spectrum under initial concentration of $200 \mathrm{mg} / \mathrm{L}$. From 0 to $11 \mathrm{~h}, 2$-picolinic acid $\left(\mathrm{A}^{265}\right) \mathrm{kept}$ unchanged, and then the peak intensity of 2-PA began to reduce at 12 $\mathrm{h}$, simultaneously, an absorption peak at $\mathrm{A}^{310}$ emerged indicating that 2-PA was bio-transferred into a new intermediate. From 13 to $18 \mathrm{~h}$, the peak intensities of $\mathrm{A}^{265}$ and $\mathrm{A}^{310}$ weakened until disappeared. TOC
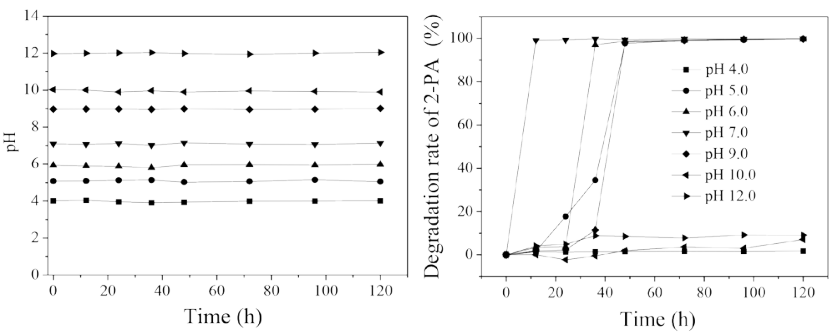

Figure 4: Effect of $\mathrm{pH}$ on the degradation of 2-PA by strain ZD3 based on buffer method: (a) $\mathrm{pH}$ changes during the degradation process; (b) degradation rates of 2-PA

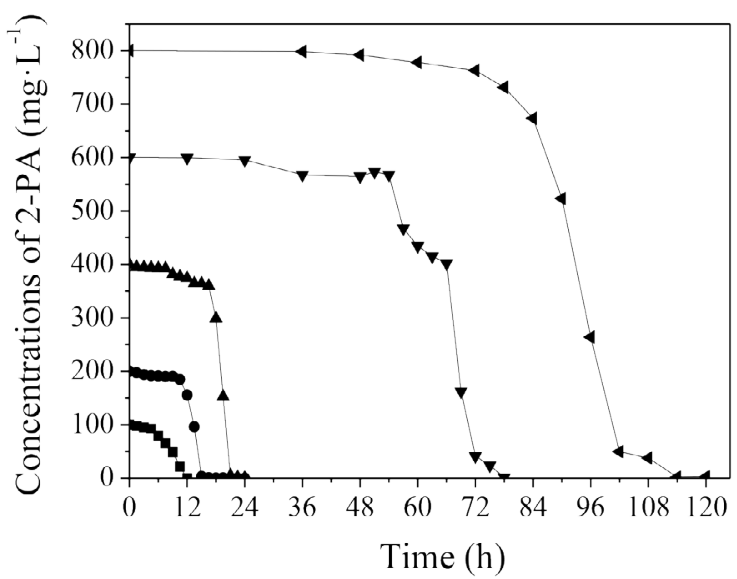

Figure 5: Effect of initial concentrations of 2-PA for degradation. 
analysis showed that the final products at $18 \mathrm{~h}$ were carbon dioxide and water. When the initial concentrations of 2-PA were 100, 400, 600 and $400 \mathrm{mg} / \mathrm{L}$, the same phenomenon were also observed.

Figure 7 presented HPLC-IT-TOF-MS of $\mathrm{A}^{310}$ at $13 \mathrm{~h}$ corresponded to Figure 6, in which $\mathrm{m} / \mathrm{z}=138.0233$ was classified as the $[\mathrm{M}-\mathrm{H}]^{-}$ adductive product of 6-hydroxy picolinic acid (6-HPA). In general, the first step for biodegradation of 2-PA is introduced a hydroxyl group on a carbon adjacent to $\mathrm{N}$ atom so that 6 -HPA is generated [1,2]. In this paper, the experimental findings were consistent with these literatures $[1,2]$. The aerobic biodegradation pathway of 2-PA by strain ZD3 will be further studied.

Degradation kinetics: The models of zero-order kinetic and firstorder kinetic were applied to express the degradation process, which based on the following equations, respectively $[13,14]$ :

$$
\begin{aligned}
& \ln c=a+k_{1} t \\
& c=b+k_{0} t
\end{aligned}
$$

where $a$ and $b$ are constants of degradation kinetics, respectively. $t$ is time, $k^{1}$ and $k^{2}$ are rate constants of zero-order kinetic and first-order kinetic, respectively.

As seen in Figure 8, the zero-order kinetic and first-order kinetic models were used to fit in the linear range of each degrading profile in Figure 5. It was found that the correlation index $\left(R^{2}\right)$ of zero-order kinetic was apparently higher than the first-order kinetic (Tables 2 and 3). $k^{0}$ increased with the increase in initial concentration (100 to 400

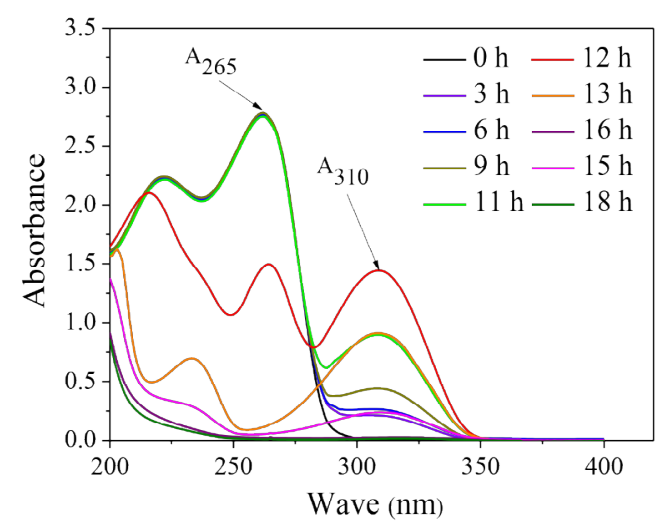

Figure 6: Ultraviolet spectra (UV) recorded the degradation and biotransformation of 2-PA.

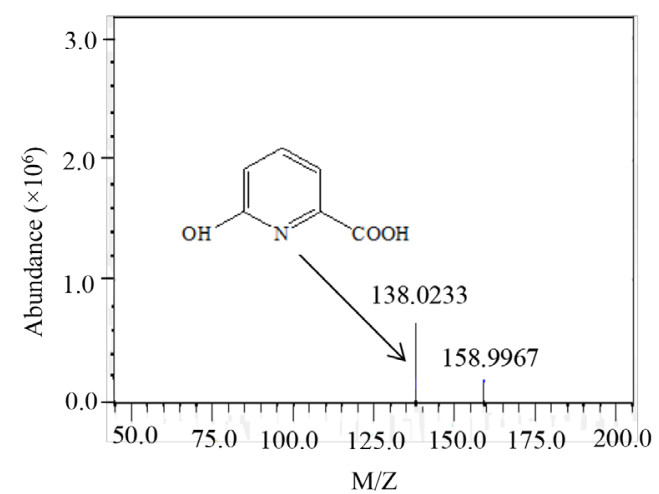

Figure 7: HPLC-IT-TOF-MS of 6-HPA.
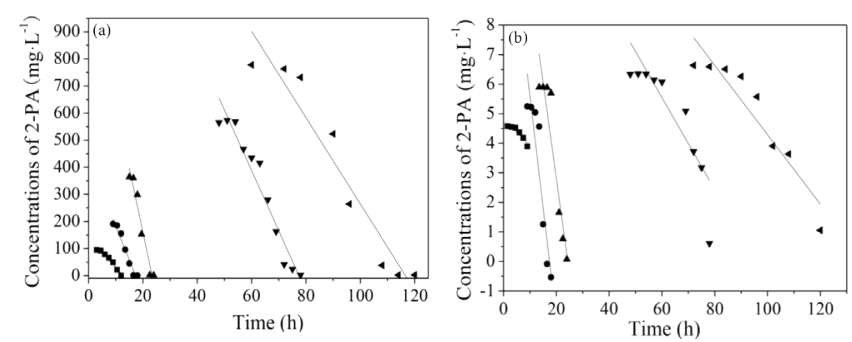

Figure 8: Degradation kinetic models: (a) zero order kinetics model; (b) first order kinetics model.

\begin{tabular}{|c|c|c|c|}
\hline Concentrations $\mathbf{( m g /} / \mathbf{L})$ & $\begin{array}{c}\text { The zero order kinetics } \\
\text { equations }\end{array}$ & $\boldsymbol{k}_{\mathbf{o}}$ & $\boldsymbol{R}^{\mathbf{2}}$ \\
\hline 100 & $\mathrm{C}=-10.867 t+139.01$ & 10.87 & 0.9518 \\
\hline 200 & $\mathrm{C}=-24.956 t+433.13$ & 24.96 & 0.9543 \\
\hline 400 & $\mathrm{C}=-47.390 t+1108.7$ & 47.39 & 0.9466 \\
\hline 600 & $\mathrm{C}=-22.296 t+1725.8$ & 22.29 & 0.9418 \\
\hline 800 & $\mathrm{C}=-15.941 t+1858.4$ & 15.94 & 0.9302 \\
\hline
\end{tabular}

Table 2: The parameters of zero order degradation dynamics model.

\begin{tabular}{|c|c|c|c|}
\hline $\begin{array}{c}\text { Concentrations } \\
\text { (mg/L) }\end{array}$ & $\begin{array}{c}\text { The first order kinetics } \\
\text { equation }\end{array}$ & $\boldsymbol{k}_{\mathbf{1}}$ & $\boldsymbol{R}^{\mathbf{2}}$ \\
\hline 100 & $\mathrm{c}=-0.0898 \boldsymbol{t}+4.8224$ & 0.09 & 0.8722 \\
\hline 200 & $\mathrm{c}=-0.7561 t+13.167$ & 0.76 & 0.8642 \\
\hline 400 & $\mathrm{c}=-0.6481 t+15.780$ & 0.65 & 0.8888 \\
\hline 600 & $\mathrm{c}=-0.1607 t+14.945$ & 0.16 & 0.7920 \\
\hline 800 & $\mathrm{c}=-0.1175 t+16.037$ & 0.12 & 0.8834 \\
\hline
\end{tabular}

Table 3: The parameters of first order degradation dynamics model.

$\mathrm{mg} / \mathrm{L})$. It might be that under such a concentration range, the carbon, nitrogen and energy for the growth of strain ZD3 was not enough so that the higher initial concentrations, the faster the degradation rate [13]. When the initial concentrations of 2-PA increased from 600 to $800 \mathrm{mg} / \mathrm{L}, k^{0}$ showed a trend of decline and the substrate inhibition effect emerged.

\section{Conclusion}

A strain utilized 2-PA as a sole carbon, nitrogen, energy sources under aerobic conditions were isolated and based on 16S rRNA gene sequence analysis it was identified as a Comamonas sp. The influence of $\mathrm{pH}$ and initial concentrations on 2-PA degradation were investigated. It was found that the optimal $\mathrm{pH}$ value was 7.0 and the required time for completely degradation was extended with the increase in initial concentration. The degradation kinetics model was established. Compared to the first order kinetics model, zero order kinetics model better expressed the degradation behavior of 2-PA.

\section{Acknowledgements}

This work was funded by National Natural Science Foundation of China (21307097), Fundamental Research Funds for the Central Universities (xjj2016046) and China Postdoctoral Science Foundation (2016M602830). We would also thank very much to the editor and anonymous reviewers for their valuable opinions.

\section{References}

1. Kaiser JP, Feng Y, Bollag JM (1996) Microbial metabolism of pyridine, quinoline, acridine, and their derivatives under aerobic and anaerobic conditions. Microbiol Rev 60: 483-498.

2. Yao YX, Tang HZ, Ren HX, Yu H, Wang LJ, et al. (2013) Iron (II)-dependent dioxygenase and $\mathrm{N}$-formylamide deformylase catalyze the reactions from 5-hydroxy-2-pyridone to maleamate. Sci Rep 3: 2-35. 
Citation: Qiaorui W, Chunli Z, Yurui F, Zhenxing S, Wenhao H, et al. (2017) Aerobic Biodegradation of 2-Picolinic Acid by a Comamonas Sp. J Environ Anal Toxicol 7: 499. doi: 10.4172/2161-0525.1000499

Page 5 of 5

3. Li KC, Zhang HB, Liu J, Cao XJ, Zhang YM (2005) Simultaneous determination of pyridine, 2-aminopyridine, 2-methylpyridine and 2-pyridinecarboxylic acid by reversed phase high performance liquid chromatography. Chin J Anal Chem 33: $1580-1582$

4. Tian YQ, Li WH (2005) A new process of synthesis of chromium-2-picolinate by chromic anhydride oxidation. Chem Eng (Chin) 9: 53-54.

5. Zheng CL, Zhou JT, Wang J, Zhao LJ, Cong LX (2006) Degradation of picolinic acid by a mixture of nitrobenzene-assimilating strains under aerobic condition. Fine Chem (Chin) 23: 1198-1120.

6. Khasaeva F, Vasilyuk N, Terentyev P, Troshina M, Lebedev AT (2011) A novel soil bacterial strain degrading pyridines. Environ Chem Lett 9: 439-445.

7. Wu B, Lin W, Gao HY, Kim C (2005) Antibacterial constituents of Senecio cannabifolius (II). Chin Tradit Herb Drugs 36: 1447-1449.

8. Zheng CL, Zhou JT, Wang J, Qu BC, Wang J, et al. (2009) Aerobic degradation of 2-picolinic acid by a nitrobenzene-assimilating strain: Streptomyces sp. Z2. Bioresour Technol 100: 2082-2084.
9. Zheng CL, Zhou JT, Zhao LH, Lu H, Qu BC, et al. (2007) Isolation and characterization of a nitrobenzene degrading Streptomyces strain from activated sludge. Bull Environ Contam Toxicol 78: 163-167.

10. Zhao Y, Xue LG, Li L, Zhang HG (2012) Advance in environmental pollutants degradation of Comamonas. Microbiology (Chin) 39: 1471-1478.

11. Chen JC, Cui MC, Chen XJ, Liu LR (2012) Study on the effects of environmental factors on the aerobic biodegradation of indole. Environ Sci Technol (Chin) 25 40-43.

12. Christopherson MJ, Yoder KJ, Hill JT (2006) Hydrophilic interaction liquid chromatographic (HILIC)/ion exchange separation of picolinic and nicotinic acids. J Liq Chromatogr Relat Technol 29: 2545-2558.

13. Song XL, Ji WK, Zhang D, Tian JM (2008) Biodegradation of pyridine by immobilized Rhodocyclus Gelatinosus. J Nanjing Univ Sci Technol (Chin) 32: 522-525.

14. Liu YL, Song YG, Guan ZY, Zhang L, Feng YL (2015) Intestinal flora degradation dynamics of saponins from pulsatillae radix in rats. Chin $\mathrm{J}$ Exp Tradit Med Formulae 21: 1-4. 